\title{
Axial Position and Speed Control of a Non-Salient Synchronous Axial Self- Bearing Motor using Dynamic Surface Control
}

\author{
Ngo Manh Tung ${ }^{1,2}$, Pham Quang Dang ${ }^{1}$, Nguyen Huy Phuong ${ }^{1}$, Nguyen Quang Dịch', \\ Nguyen Danh Huy ${ }^{1}$, Nguyen Tung Lam ${ }^{*}$ \\ ${ }^{1}$ Hanoi University of Science and Technology, Hanoi, Vietnam \\ ${ }^{2}$ Hanoi University of Industry, Hanoi, Vietnam \\ *Email: lam.nguyentung@hust.edu.vn
}

\begin{abstract}
The paper focuses on the controller designing for the position and speed of non-salient synchronous type axial self-bearing motors. The motor creates the magnetic field to lift the motor along the shaft and generate rotating torque. Firstly, the motor electro-mechanical relations are analyzed to formulate an accurate mathematical model, then a vector control structure is proposed. The force components control the axial position, and the torque controls the motor speed. Secondly, based on the Lyapunov stability function, the dynamic surface control is used to design position and speed controllers. The system simulation results show that the drive system ensures stability and tracking performance. In addition, the interaction between position and speed loops of the control loop is also negligible
\end{abstract}

Keywords: Axial gap type synchronous self-bearing motor, magnetic bearing motor, dynamic surface control, lyapunov function.

\section{Introduction}

In recent years, motors with integrated magnetic bearings have received more and more attention due to its advantages compared to traditional ball bearings [1]. Integrated magnetic bearing motor applications include special conditions requiring low friction, high speed requirements, working environment temperatures that are too high or too low or requiring sterility. The problem of improving control quality for magnetic drive motors has prompted the use of different control engineering methods.

The motor studied in this paper is a synchronous motor with permanent magnets attached to the rotor and the two stators with windings on both sides of the rotor. The motor structure is shown in Fig. 1. Assuming that the motor shaft has been stabilized by the radial magnetic bearings, the object then has two degrees of freedom: rotation and displacement along the rotor axis [2-4].

This structure is defined as a self-lifting AC motor with axial clearance, which is called Axial Flux Permanent Magnetic machine (AFPM). The AFPM motor is a combination of axial magnetic motor with radial magnetic drive, due to reduced hardware configuration, it is simpler in structure and control than conventional integrated magnetic bearing motor. The AFPM motor can be either asynchronous or synchronous. However, synchronous motors have received more attention due to their high efficiency and power factor and are easy to manufacture [5-6]. If the synchronous motor is non-salient, the inductance components on two axes $d$ and $q$ are different, and a reluctance torque appears, which causes difficulties in decoupling control between the position and speed control loops.

The control method for AFPM motor is based on vector control principle, in which $i_{d}$ current is used to control axial force, and $i_{q}$ current controls rotational torque [7]. In [1-2] authors used PI and PID controllers that regulate the axial position and speed. However, the used equations and are strongly nonlinear. Therefore, an option of using nonlinear controllers is necessary. Dynamic surface control method is used to design the controller. This is a technique applied to nonlinear system objects, used to control the tracking and stability of the system [8-11]. The technique of dynamic surface control (DSC) carries the specification of backstepping and multi-surface sliding control (MSS) [14-16]. However, it has been added with a first-order filter to avoid explosion of term. The simulation results show that the proposed controller has the position and speed responses following the trajectory set in a fast time. The system is also stable to the interleaving effects of the two control loops. 


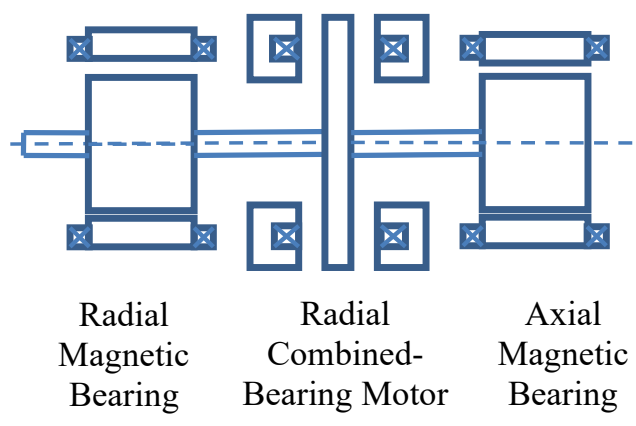

Fig. 1. Structure of AFPM

This paper is organized as follows. In second section, the mathematical model of AFPM motor and control principle are introduced. In third section, the DSC controllers are designed. Simulation and experiment are demonstrated in fourth section, which is followed by conclusion in fifth section.

\section{Control Principle}

The structure of a permanent magnet synchronous motor with integrated magnetic bearing is shown in Fig. 2. The rotor is lifted by two magnetic bearings from the radial axis. Motions in $x, y, \theta_{x}, \theta_{y}$ directions of the rotor is assumed to totally controlled by the radial magnetic bearings.

The scope of the paper only focuses on rotational and translational motion in the $z$-axis, hence the motor consists of two degrees of freedom. The rotor is a flat disc with permanent magnets mounted on the rotor surface (nonsalient-pole rotor) or mounted in the rotor surface groove (salient-pole rotor). On each side of the rotor is a stator, on each stator there are three threephase windings creating a rotating magnetic field in the air gap. This magnetic field will generate torques $T_{1}$ and $T_{2}$ on the rotor and attractive forces $F_{1}$ and $F_{2}$ between the rotor and each stator. The total torque $T$ is calculated as the addition of the two component moments. The axial force $F$ is calculated as the difference of the two component axial forces. They are regulated by the amplitude and phase angle of the currents across the two stators. If the axial magnetic field force is unstable, an axial position control signal is required to stabilize the axial motion [1] and [3]. The mathematical model of the motor is presented on the coordinate system based on the rotor magnetic flux $(d, q)$ or the stator coordinate system $(\alpha, \beta)$.

When presenting the mathematical model of the motor, it is important to note that the permanent magnet arrangement on the rotor affects the inductance on the stator winding. The paper considers the salientpole motor with stator inductance as a function of the rotor angle position and air gap between the stator and the rotor. synchronous motor with integrated magnetic bearing

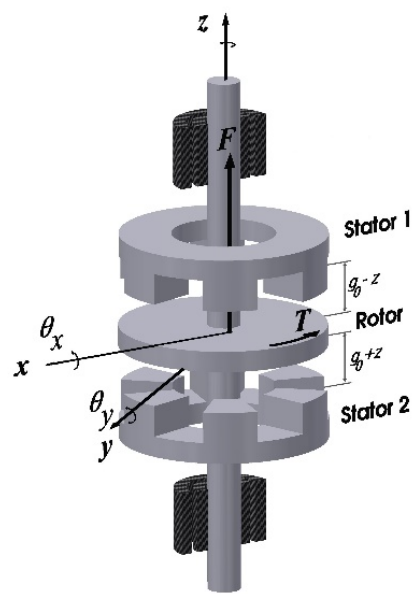

Fig. 2. The structure of a permanent magnet

This inductance is inversely proportional to the airgap and it is presented by the following approximation formula:

$$
\begin{aligned}
& L_{s d}=\frac{3}{2} \frac{L_{s d 0}^{\prime}}{g}+L_{s l} \\
& L_{s q}=\frac{3}{2} \frac{L_{s q 0}^{\prime}}{g}+L_{s l}
\end{aligned}
$$

where $L_{s d 0}^{\prime}$ and $L_{s q 0}^{\prime}$ are the $d$ - axis and $q$ - axis inductance per gap unit; $L_{s l}$ is leakage inductance; $g=g_{0} \pm z$ is clearance between stator and rotor; $g_{0}$ is clearance at equilibrium position; $z$ is displacement from the equilibrium position.

The mathematical model of the synchronous motor represented on the axis system creating the rotation $d, q$ is as follows [7], [14]

$$
\left\{\begin{array}{l}
u_{s d}=R_{s} i_{s d}+L_{s d} d_{i_{s d}} / d t-\omega_{e} L_{s q} i_{s q} \\
u_{s q}=R_{s} i_{s q}+L_{s q} d_{i_{s q}} / d t+\omega_{e} L_{s d} i_{s d}+\omega_{e} \lambda_{m} \\
\lambda_{s d}=L_{s d} i_{s d}+\lambda_{m} \\
\lambda_{s q}=L_{s q} i_{s q}
\end{array}\right.
$$

where $i_{s d}$ and $i_{s q}$ are stator current components. $u_{s d}$ and $u_{s q}$ are stator voltage components, $\omega_{e}$ is the rotor speed, $\lambda_{s}$ is the stator flux, $\lambda_{m}$ is the magnitude of the flux linkage between the rotor and the stator. Calculating the axial force and rotational torque for a stator and then summarizing lead to a general mathematical model for the motor.

According to [1-3] the torque is controlled by the current on the $q$-axis, and the axial force is controlled by the current on the $d$-axis. We assume that:

$$
\left\{\begin{array}{l}
i_{q 1}=i_{q 2}=i_{q} \\
i_{d 1}=i_{d 0}-i_{d} \\
i_{d 2}=i_{d 0}+i_{d}
\end{array}\right.
$$


in which: $i_{d 1}$ and $i_{d 2}$ are the axial current components on the two stators, respectively, $F_{1}$ and $F_{2}$ are generating axial forces; $i_{d 0}$ is the offset current which has a very small value or is close to zero. The axial force and the total torque caused by the two stators acting on the rotor [1] are:

$$
\begin{gathered}
F=4 K_{F d} i_{f} i_{d}+\left\{4 K_{F d}\left(i_{d}^{2}+i_{f}^{2}\right)+4 K_{F q} i_{q}^{2}\right\} \frac{z}{g_{0}} \\
T=2 K_{T} i_{q}+2 K_{R} i_{d} i_{q} \frac{z}{g_{0}}
\end{gathered}
$$

If the displacement is zero or very small relative to the gap at the equilibrium $g_{0}$, then (2) and (3) can be reduced to:

$$
\begin{aligned}
& F=4 K_{F d} i_{f} i_{d} \\
& T=2 K_{T} i_{q}
\end{aligned}
$$

From (13) and (14) we see that, although the axial force is still subject to a small dependence on the current component on the $q$-axis and the rotational torque is still subject to a small dependence on the current component on the $d$-axis, it can control the axial force by current $i_{d}$ and the torque by $i_{q}$ current. The system control structure is based on the principle of vector control based on the rotor flux on the $d q$ coordinate system, with the axis $d$ coincident with the rotor flux vector $[2,7,15,16]$.
The symbol $z$ is the axial position from the balance point as determined by the position sensor. This value is compared with the control value $z_{\text {ref }}$ (this value is always set to zero to ensure the rotor is in the center position between the two stators).

The $q$ axis current components are controlled by the reference values obtained from the speed controller, and the $d$ axis current components are controlled by the reference values obtained from the axial position controller. The output of the current controller is used to calculate the reference voltage values. We need to use the step of converting the rotation coordinate system to the stator three-phase fixed reference system. The direct current to the stator phases of the AGBM is supplied from the PWM pulse width modulators. The position and speed controllers are synthesized by dynamic surface control (DSC) method.

\section{Dynamic Surface Control (DSC)}

\subsection{Dynamic Surface Control Method}

Dynamic surface control technique is developed based on Backstepping technique and multi-sliding surface control. The n-order tight backpropagation nonlinear system is divided into $\mathrm{n}$ subsystems, each of which can find a virtual control law similar to Backstepping technique. The dynamic surface control

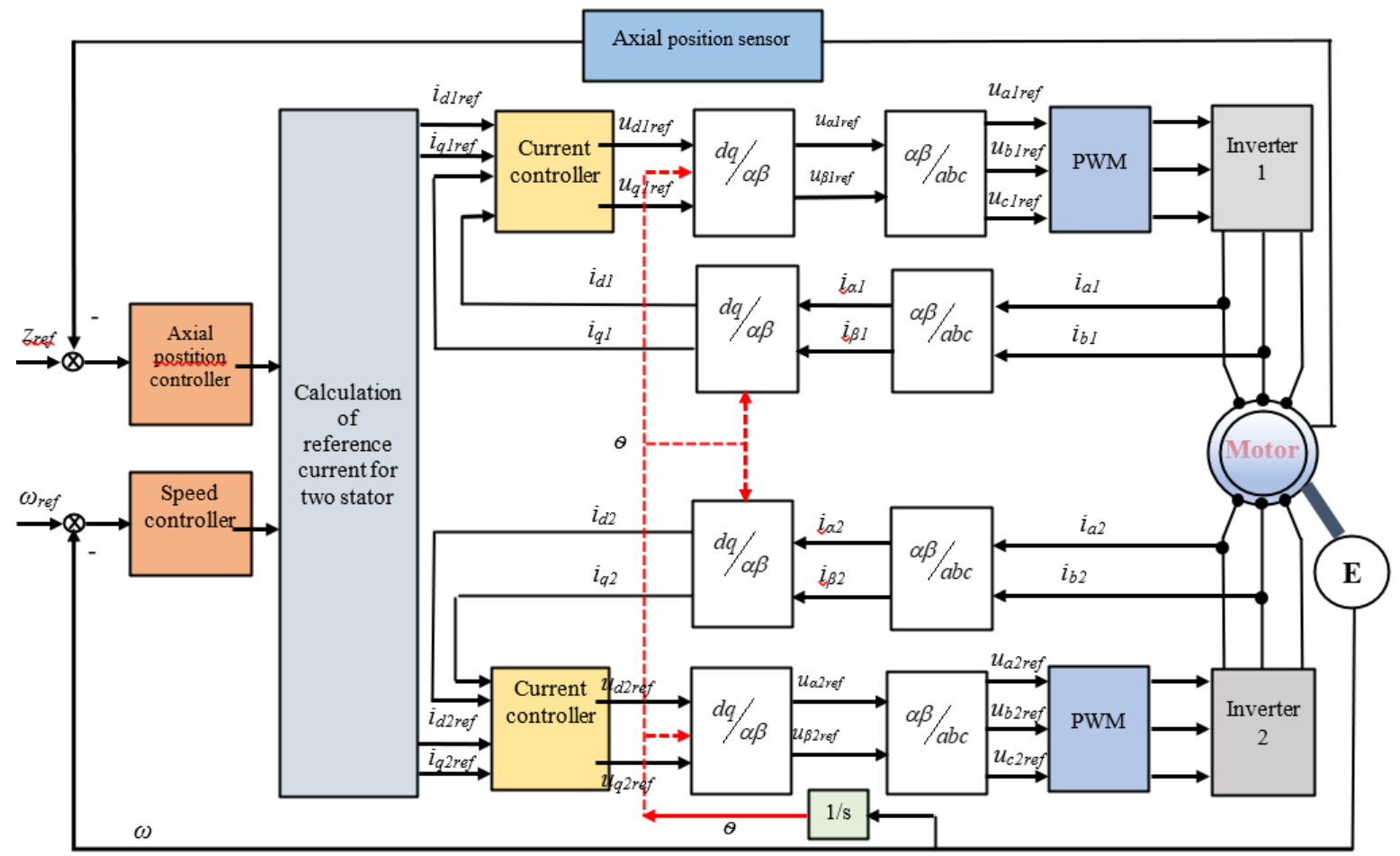

Fig. 3. The control structure of the AFPM motor 
method uses an additional first-order filter in each step, so that DSC overcomes the disadvantage of operand explosion of Backstepping and MSS methods [10]. system:

Consider the following tight response nonlinear

$$
\left\{\begin{array}{l}
\dot{x}_{1}=f_{1}\left(x_{1}\right)+g_{1}\left(x_{1}\right) x_{2} \\
\dot{x}_{i}=f_{i}\left(x_{i}\right)+g_{i}\left(x_{i}\right) x_{i+1} \\
\dot{x}_{n}=f_{n}\left(x_{n}\right)+g_{n}\left(x_{n}\right) u \\
y=x_{1}
\end{array}\right.
$$

where $\bar{x}_{n}=\left[x_{1}, x_{2}, \ldots, x_{n}\right]^{T} \in R^{n}$ is the system state vector, $u \in R$ is the input to the system, $y \in R$ is the output to the system, $f_{i}$ (.) and $g_{i}$ (.) with $i=1,2 \ldots, n$ are known nonlinear parameter functions of the system. To ensure strict backpropagation of the system we need $g_{i}() \neq$.0 .

The control objective is to find the control law $u$ so that the system is stable, the system output follows the desired set signal $y=x_{l}=x_{d}$.

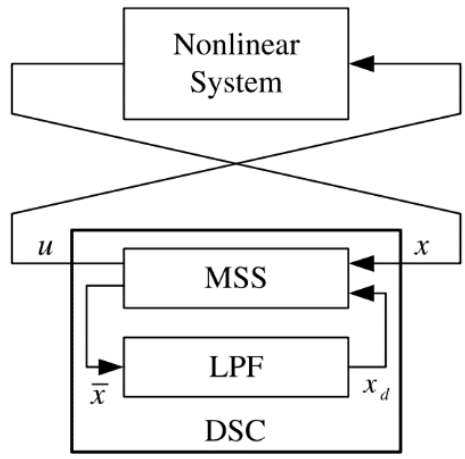

Fig. 4. DSC system structure

\subsection{Axial Position Controller}

The radial position of the rotor is stabilized by the horizontal magnetic bearing, so the axial displacement will be independent of the axial displacement, and is calculated as follows:

$$
m . \ddot{z}=F-F_{L}
$$

where $m$ is the mass of the moving component, $F$ is the axial force, and $F_{L}$ is the axial load. According to (4) we have:

$$
\ddot{z}=\frac{1}{m}\left(F-F_{L}\right)=\underbrace{\frac{4 K_{F d} i_{f}}{m}}_{P} i_{d}-\underbrace{\frac{F_{L}}{m}}_{Q}
$$

where $K_{z}=-4\left\{K_{F d}\left(i_{f}^{2}+i_{d}^{2}\right)+K_{F q} i_{q}^{2}\right\} / g_{0}$ is the stiffness coefficient of the motor and $K_{m}=4 K_{F d} i_{f}$ is the force amplification factor.
The position control loop generates the position control $i_{\text {dref }}$ signal $z$ to zero. Sliding surface definition:

$$
\begin{aligned}
& S=\dot{z}+\lambda z(\text { where } \lambda>0) \\
& \dot{S}=\ddot{z}+\lambda \dot{z}=P i_{d}-Q+\lambda \dot{z}
\end{aligned}
$$

According to the DSC method [8], the virtual control signal is determined:

$$
i_{d}=\frac{Q}{P}-\frac{\lambda \dot{z}}{P}-C_{z} \cdot \operatorname{sat}(S)
$$

where $C_{z}>0$. The virtual control signal is passed through the first-order filter to obtain the reference signal:

$$
\dot{i}_{\text {dref }}=\frac{i_{d}-i_{\text {dref }}}{\tau_{z}}
$$

where $\tau_{z}>0$ is the time constant. At this step, we select $\tilde{i}_{d}=i_{d r e f}-i_{d}$.

Consider the control Lyapunov candidate function:

$$
V=\frac{1}{2} S^{2}+\frac{1}{2} \tilde{i}_{d}^{2}
$$

Taking derivative of (14) results in:

$$
\dot{V}=S \dot{S}+\tilde{i}_{d} \dot{\tilde{i}}_{d} \leq 0
$$

Then the time constant needs to be satisfied:

$$
\tau_{z} \leq \frac{\varepsilon_{z}}{A^{2}}
$$

where $\mathrm{A}>0$ and is the intercept limit value $\left|i_{d}\right| \leq A$. The position control loop will stabilize after a finite time with $z$ approaching the slip surface $S$ [9-10].

\subsection{Speed Controller}

The difference between the electromagnetic torque $T$ and the load torque $T_{L}$ creates the acceleration that follows the mechanical characteristics of the motor:

$$
T-T_{L}=J \frac{d \omega}{d t} \text { or } \dot{\omega}=\frac{T-T_{L}}{J}
$$

According to (4) we have:

$$
\dot{\omega}=\underbrace{\frac{2 K_{T}}{J}}_{M} i_{q}-\underbrace{\frac{T_{L}}{J}}_{N}
$$

The speed control loop can be expressed as:

$$
x=\omega, y=\omega, u=i_{q}, \dot{x}=\dot{\omega}=M i_{q}-N
$$


The speed control requires $\omega$ to track to the set speed value $\omega_{d}$. The definition of the sliding surface is as follows:

$$
z_{l}=\omega-\omega_{d}
$$

The virtual control signal:

$$
i_{q}=\frac{-c_{\omega} z_{1}}{M}+\frac{N-\omega_{d}}{M}
$$

where coefficient $>0$. The $i_{q}$ current is passed through the first-order inertia filter to get the reference signal $i_{\text {qref. }}$

$$
\dot{i}_{q r e f}=\frac{i_{q}-i_{q r e f}}{\tau_{\omega}}
$$

where $\tau_{\omega}>0$ is a time constant. Defining the current tracking error as

$$
\tilde{i}_{q}=i_{\text {qref }}-i_{q}
$$

Consider the control function Lyapunov:

$$
V=\frac{1}{2} z_{1}^{2}+\frac{1}{2} \tilde{i}_{q}^{2}
$$

With the way of determining the control signal as above we have:

$$
\dot{V}=z_{1} \dot{z}_{1}+\tilde{i}_{q} \dot{\tilde{i}}_{q} \leq 0
$$

then the time constant needs to be satisfied:

$$
\tau_{\omega} \leq \frac{\varepsilon_{\omega}}{B^{2}}
$$

where $B>0$ and is the intercept limit value $\left|\dot{i}_{q}\right| \leq B$.

The speed control loop will stabilize after a finite time with the slip surface $z_{1}$ approaching 0 or the output trajectory of the speed loop $\omega$ approaching the set trajectory $\omega_{d}$.

\section{Simulation and Results}

To demonstrate the system control capability of the proposed structure, simulations were performed on Matlab Simulink software. With the parameters of the motor including phase resistance is $2.6 \Omega$; the air gap between the stator and the rotor is $2 \mathrm{~mm}$; The rotor mass is $0.28 \mathrm{~kg}$, the moment of inertia is $10.6 \times 10^{-6} \mathrm{kgm}^{2}$, the loop flux amplitude generated by the permanent magnet is $\lambda_{m}=0.022 \mathrm{~Wb}$.

Consider the drive system operating in the absence of load disturbances. Initially, the rotor is offset from the equilibrium position by $0.3 \mathrm{~mm}$, the speed is set at $250 \mathrm{rad} / \mathrm{s}$. The axial position and speed responses are shown in Fig. 5. The $z$ position oscillates with an amplitude of $0.05 \mathrm{~mm}$ and returns to the equilibrium position after a time interval of $0.02 \mathrm{~s}$. Meanwhile, the speed is accelerated towards the set value and stabilizes at that value after $0.12 \mathrm{~s}$ time interval. The speed overshoot is almost negligible.

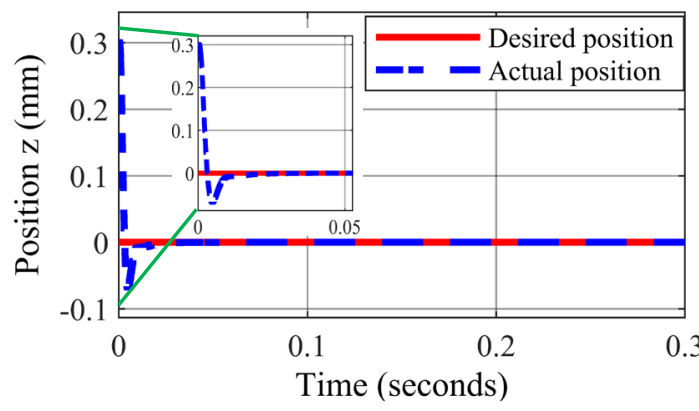

(a)

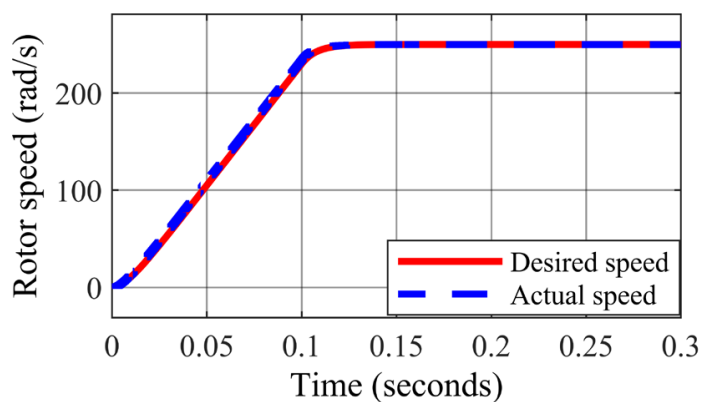

(b)

Fig. 5. Response of position and speed without load interference

Fig. 6 shows the response of two current components on the $d q$ coordinate system. Flux forming current $i_{d}$ fluctuates with an overshoot of $2.5 \mathrm{~A}$ and stabilizes after $0.02 \mathrm{~s}$. It is this current that corrects the stable and balanced axial position after the same period of time. Torque generating current $i_{q}$ reference current acts as the acceleration of the speed. So, during the transient period, the $i_{q}$ current has a large value of $0,82 \mathrm{~A}$. After $0.15 \mathrm{~s}$, the current drops and stabilizes, stopping the fluctuation of the speed response.

In order to test the responsiveness of the speed controller, consider the case of changing the speed setting from $150 \mathrm{rad} / \mathrm{s}$ to $250 \mathrm{rad} / \mathrm{s}$. The results in Fig. 7 show that the speed response only needs $0.08 \mathrm{~s}$ to be asymptotic and stable with the set value when the overshoot is negligible. Torque generating $i_{q}$ current has a large value during the transient period and is zero when the speed does not change. 
JST: Smart Systems and Devices

Volume 31, Issue 2, September 2021, 100-107

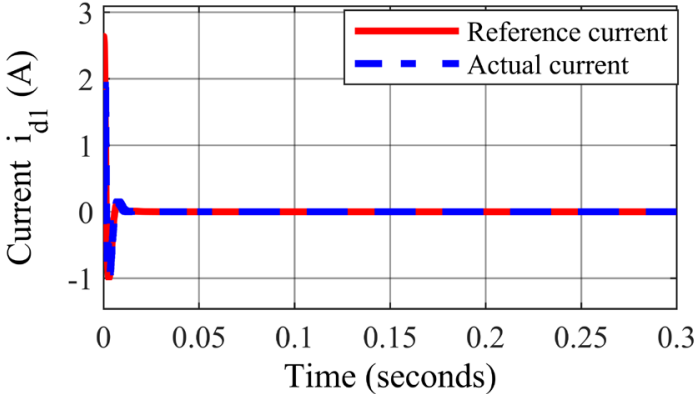

(a)

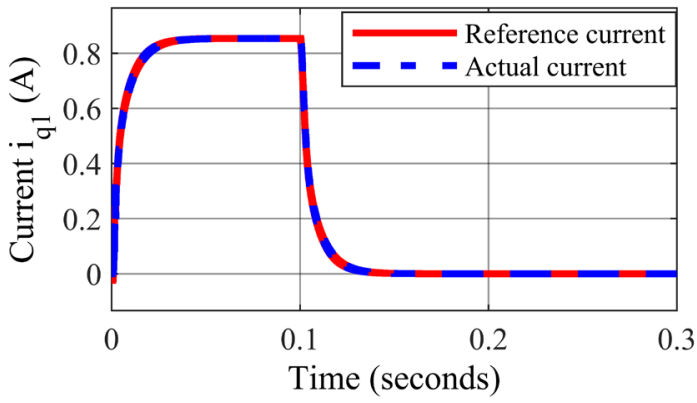

(b)

Fig. 6. The $i_{d}$ and $i_{q}$ current in the absence of load disturbance

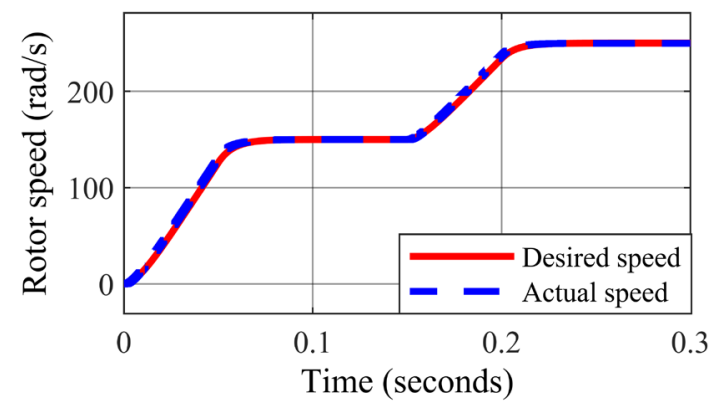

(a)

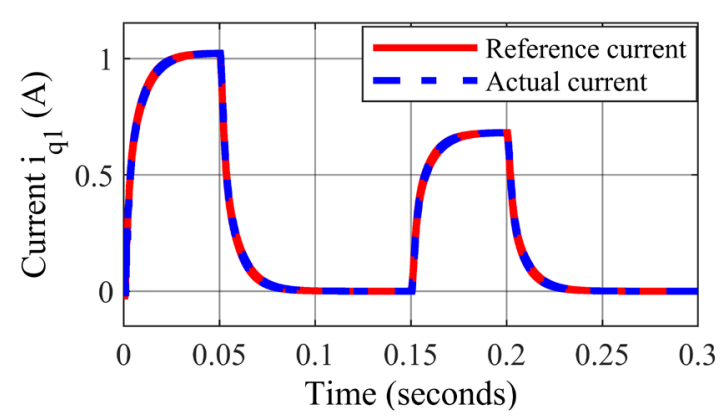

(b)

Fig. 7. Response speed and $i_{q}$ current when changing speed set value

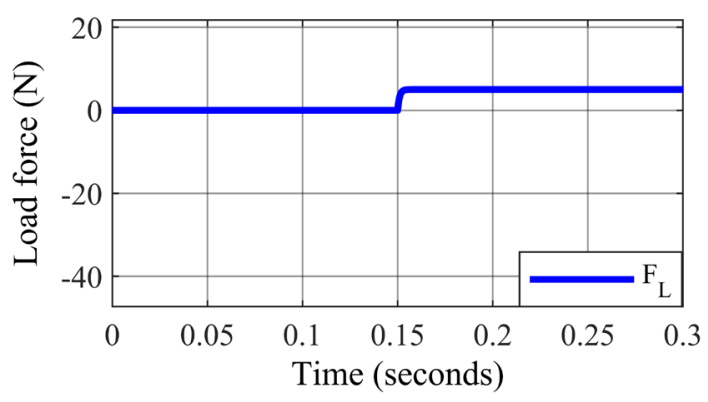

(a)

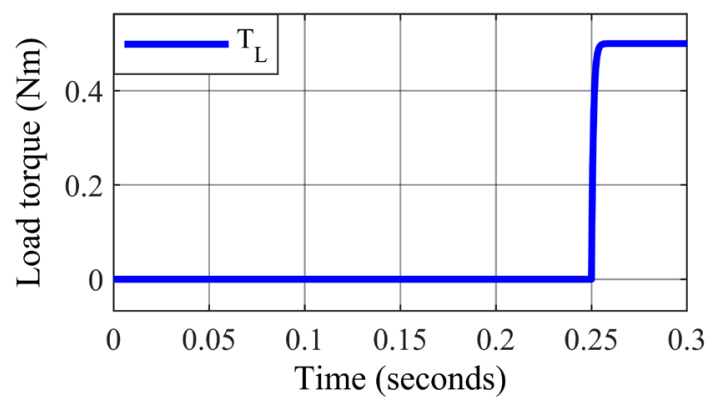

(b)

Fig. 8. Load disturbance and load torque in simulation

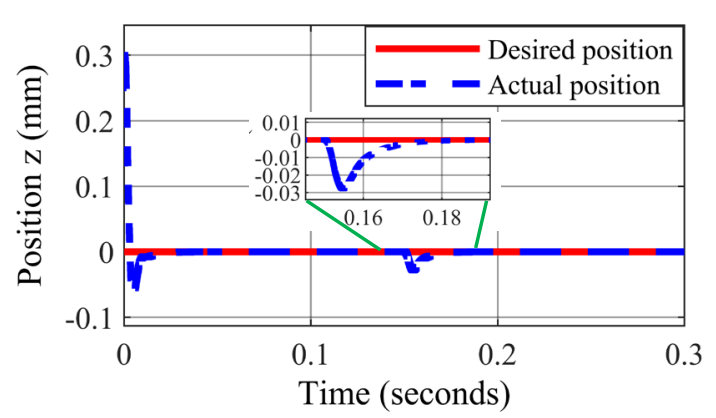

(a)

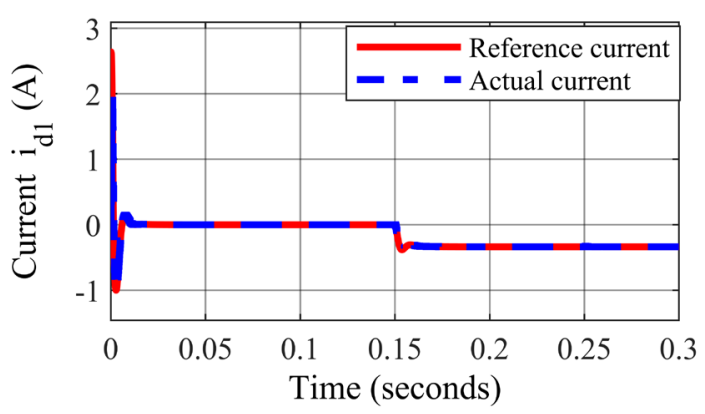

(b)

Fig. 9. Response of $i_{d}$ current and axial position in the presence of load disturbance 


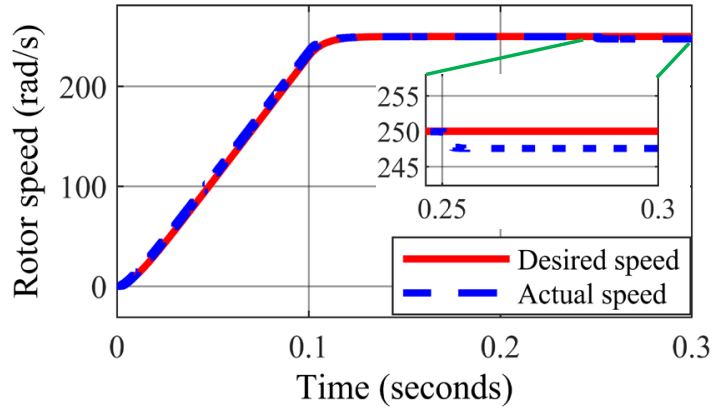

(a)

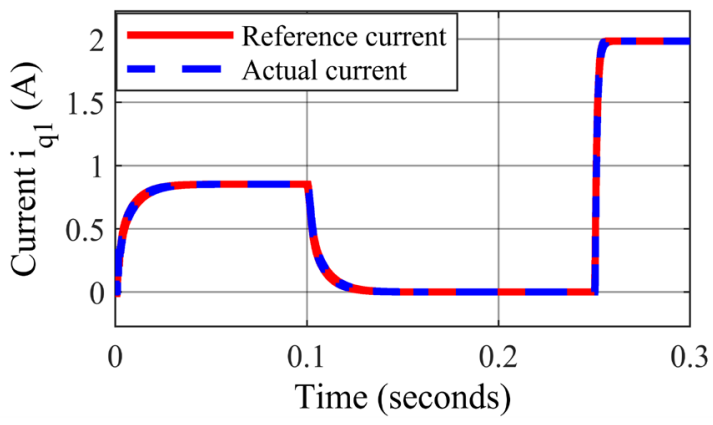

(b)

Fig. 10. Response of $i_{q}$ current and speed in the presence of load disturbance and load torque

Consider the effect of axial load on the system by assuming that at the instant of $0.15 \mathrm{~s}$ there is an applied load. The results on graph of Fig. 9 show that the axial position fluctuates as soon as the axial load occurs. Flux forming $i_{d}$ reference current signal at the position controller output is increased to stable state with the load noise after about $0.03 \mathrm{~s}$.

Correspondingly, the $z$-axis position fluctuates and stabilizes at the equilibrium point at $0.18 \mathrm{~s}$.

The speed response on the graph of Fig. 9 shows that the speed is almost unaffected by the axial force. This means that the system has eliminated the interaction of the elements on the $d$ axis to the elements on the $q$ axis.

To check the robustness of the system, we consider the case when there is a load torque acting at $0.25 \mathrm{~s}$. Fig. 10 shows that the $i_{q}$ reference current signal at the output of the speed controller increases as soon as the load torque appears. This is to produce a sufficiently large torque value on the motor shaft to compensate for the load noise. The $i_{q}$ current stabilizes after about $0.02 \mathrm{~s}$. Corresponding to this, we have a slightly fluctuating and stable speed at the set value at $0.27 \mathrm{~s}$.

Fig. 11 shows that the impact of the load torque on the axial position is negligible. Therefore, it can be said that the system has eliminated the influence of the

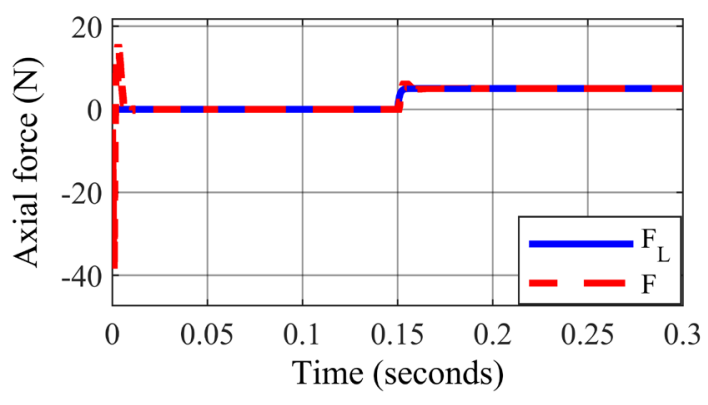

(a)

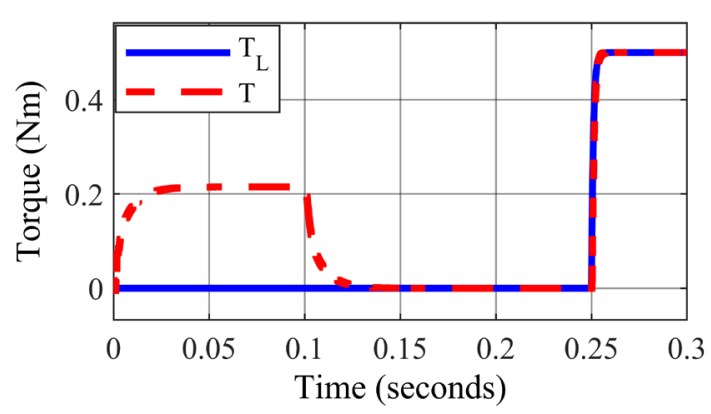

(b)

Fig. 11. Response of axial force and torque in the presence of load disturbance and load torque

inter-channel interaction between the speed loop and the axial position loop.

\section{Conclusion}

This paper has designed and built a position and speed control transmission system for the axial gap flux motor, applying the DSC dynamic surface control method. The motor operates with torque and axial force generated from the current components on the $d$ and $q$ axis. The simulation results show that the designed position controller and speed controller can control the system stably, fast setting value with low overshoot. At the same time, it is possible to limit the interaction between the speed control loop and the axial position control loop.

\section{Acknowledgment}

This research was funded by Hanoi University of Science and Technology.

\section{References}

[1]. Quang-Dich Nguyen and Satoshi Ueno (October 6th 2010). Salient pole permanent magnet axial-gap selfbearing motor, Magnetic Bearings, Theory and Applications, Bostjan Polajzer, IntechOpen, https://doi.org/10.5772/intechopen.83966

[2]. Dich, Nguyen, and S. Ueno, Axial position and speed vector control of the inset permanent magnet axial gap type self-bearing motor, IEEE/ASME Int. Conf. Adv. Intell. Mechatronics, AIM, pp. 130-135, 2009. https://doi.org/10.1109/AIM.2009.5230025 
[3]. Q. D. Nguyen and S. Ueno, Analysis and control of nonsalient permanent magnet axial gap self-bearing motor, IEEE Trans. Ind. Electron., vol. 58, no. 7, pp. 2644-2652, 2011. https://doi.org/10.1109/TIE.2010.2076309

[4]. U. S. and O. Y., Characteristics and control of a bidirectional axial gap combined motor-bearing, IEEE Trans. Mechatronics, vol. Vol. 5, No, 2000.

[5]. T. U. Jung, J. H. Jang, and C. S. Park, A Back-EMF estimation error compensation method for accurate rotor position estimation of surface mounted permanent magnet synchronous motors, Energies, vol. 10, no. 8, 2017.

https://doi.org/10.3390/en10081160

[6]. Z. Ma and X. Zhang, FPGA Implementation of sensorless sliding mode observer with a novel rotation direction detection for PMSM drives, IEEE Access, vol. 6 , pp. 55528-55536, 2018.

https://doi.org/10.1109/ACCESS.2018.2871730

[7]. N.P.Quang, J.-A.Dittrich, Vector Control of ThreePhase AC Machines, Springer, 2008.

[8]. S. Luo, J. Wang, Z. Shi, and Q. Qiu, Output feedback adaptive dynamic surface control of permanent magnet synchronous motor with uncertain time delays via RBFNN, Discret. Dyn. Nat. Soc., vol. 2014, 2014. https://doi.org/10.1155/2014/315634

[9]. R. He and Q. Han, Dynamics and stability of permanent-magnet synchronous motor, Math. Probl. Eng., vol. 2017, 2017.

https://doi.org/10.1155/2017/4923987
[10]. B. S. J. K. Hedrick, Dynamic Surface Control of Uncertain Nonlinear Systems, Springer-Verlag London. 2011, XIV, 254.

[11]. Y. H. Lan and Lei-Zhou, Backstepping control with disturbance observer for permanent magnet synchronous motor, J. Control Sci. Eng., vol. 2018. https://doi.org/10.1155/2018/4938389

[12]. C. Wang and Y. Lin, Robust adaptive dynamic surface control for a class of MIMO nonlinear systems with unknown non-symmetric dead-zone, Asian J. Control, vol. 16, no. 2, pp. 478-488, 2014. https://doi.org/10.1002/asjc.708

[13]. Z. J. Yang, T. Nagai, S. Kanae, and K. Wada, DYnamic surface control approach to adaptive robust control of nonlinear systems in semi-strict feedback form, vol. 16, no. 1. IFAC, 2005.

[14]. X. Zhang, Y. Lin, and C. Wang, Adaptive dynamic surface control for pure-feedback nonlinear systems with saturated hysteresis and uncertainties, vol. 44, no. 1 PART 1. IFAC, 2011.

[15]. I. Press, L. Shafer, G. W. Arnold, and D. Jacobson, Analysis of Electric Machinery and Drive Systems. 2013.

[16]. D. W. Novotny and T. A. Lipo, Vector Control and Dynamics of AC Drives, Clarendon Press; 1st edition, September 26, 1996. 